\title{
Interfacility helicopter transfers for critically ill patients: always the right choice?
}

\author{
Hasan Hawilo and Ravi Taneja*
}

Keywords: Helicopter emergency medical services, Interfacility transport, Critical care

\section{Introduction}

A mechanically ventilated patient was transported by air ambulance from a community hospital intensive care unit (ICU) to a leading tertiary center. Door-todoor travel time was $42 \mathrm{~min}$, which included $12 \mathrm{~min}$ airborne and $30 \mathrm{~min}$ of transfer time. With only 58 $\mathrm{km}$ between the referring and receiving hospital, a ground ambulance under similar conditions would have taken $46 \mathrm{~min}$. While it is intuitive to believe that air is generally quicker and hence better than a ground transfer, was the decision appropriate? How should critical care physicians decide when to use a limited and expensive resource like helicopter emergency medical services (HEMS) for their patients?

To date, research on HEMS has focused almost exclusively on retrospective studies of "scene" transfers, where helicopter teams rescue patients from the outof-hospital environment. However, interfacility transport (IFT), the flight between two hospital facilities, makes up over $80 \%$ of HEMS patient flights in Canada [1-3]. Given that the majority of HEMS IFT are for ICU patients and involve a door-to-door estimated driving time of less than $60 \mathrm{~min}$ [4], this editorial will discuss (1) whether HEMS IFT is indeed superior in terms of clinical outcomes, cost-effectiveness, and transport time as compared to ground emergency medical services (GEMS) and (2) the factors that ought to be considered when choosing the mode of transport for critically ill patients.

* Correspondence: ravi.taneja@lhsc.on.ca

Western University, London, Canada

\section{Healthcare outcomes and utilization}

The added benefit of IFT HEMS on healthcare outcomes is questionable. Since many HEMS systems are staffed with physicians $[5,6]$ (as opposed to basic life support (BLS) certified staff in GEMS), it is possible that HEMS patients may have improved outcomes from the care provided by the in-flight physician [7]. However, data from North America suggests that when both HEMS and GEMS patients receive care from advanced life support (ALS) certified providers, HEMS IFT does not decrease patient mortality, morbidity, or disability [7]. Furthermore, by controlling for injury severity and patient demographics, retrospective analyses have demonstrated that HEMS IFT does not reduce healthcare utilization, as measured by ICU and hospital length of stay $[7,8]$.

\section{Cost and cost-effectiveness}

HEMS IFT is costly but is not necessarily cost-effective. In Canada, government funding for the Ontario air ambulance program, Ornge, totals over $\$ 135$ million annually [9]. A recent systematic review attempting to investigate the cost of HEMS and GEMS suggests that HEMS costs more than $\$ 15,000$ per trip and is up to seven times more expensive than GEMS, without imparting a patient benefit [10]. Furthermore, HEMS flights have a higher rate of fatal accidents than other forms of air travel, and HEMS aircrews have been considered the occupation with the highest rate of workrelated fatal accidents [11]. Carbon emissions with HEMS use is greater as well as compared to other forms of road transport. Indeed, a single 4-h helicopter flight produces as much carbon emissions as a typical 
passenger car will emit in a year [12,13]. Given that half of HEMS flights are classified as non-emergency [3], even minor reductions in medically inappropriate HEMS use could lead to meaningful savings.

\section{Predicted and actual transport time}

While HEMS IFT may benefit critically ill patients traveling long distances, short-distance HEMS IFT is not necessarily faster than GEMS in regions where GEMS services are readily available [8]. Compared with GEMS, requests for HEMS are associated with longer response times at the referring hospital between the decision to transfer and departure $[8,14]$. In facilities without onsite helipads, HEMS has also been shown to lead to longer total transport time [8]. Furthermore, Ornge HEMS IFT dispatch teams underestimate the actual time to definitive care in nearly $90 \%$ of cases [15]. On average, these flights arrive $71.5 \mathrm{~min}$ later than expected [15]. While local system considerations may limit the generalizability of such results, it does signify a need to re-evaluate the assumption that air ambulance is always faster.

\section{Conclusion}

Factors such as local weather conditions, the severity and urgency of patient illness, availability of trained personnel, and anticipated time for local HEMS dispatch as well as the likely duration of travel time should be considered before seeking HEMS (Fig. 1). For the most part, this local information is readily available when interfacility transfers are being discussed. Some degree of overtriage, flights wherein patients receive air

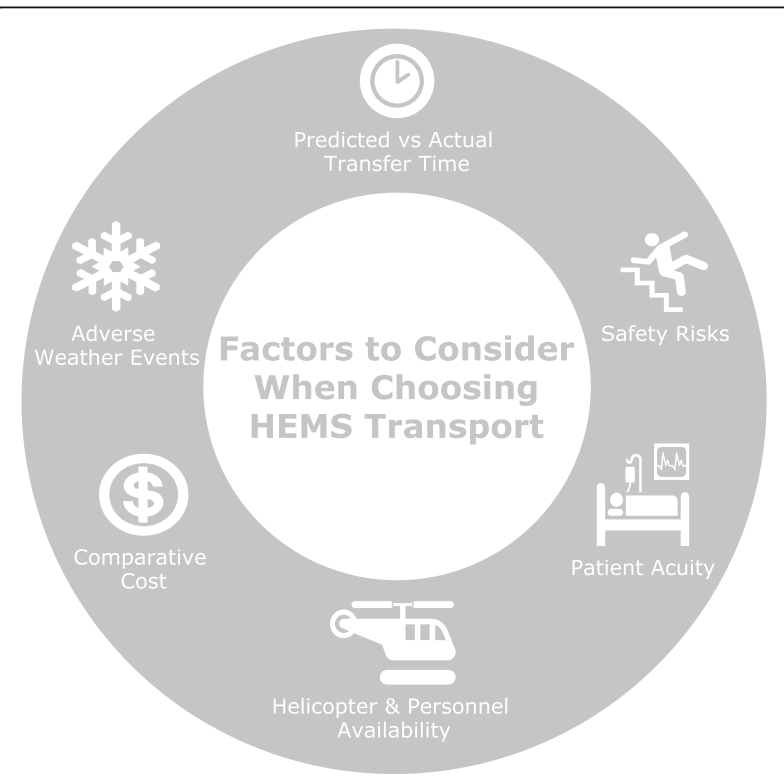

Fig. 1 Factors to consider when choosing HEMS transport ambulance transport despite not needing it, will always be inevitable, especially in scene transfers from an outof-hospital environment in as yet unstable patients [1, 7]. During an IFT, however, physicians may have substantial diagnostic information and have stabilized their patients at the referring hospital, obviating the need for overtriage. It is, therefore, recommended that physicians at both referring and receiving hospitals communicate with each other, specifically about the mode of transfer that best suits the individual patient's needs [11]. Policymakers and critical care physicians should be able to justify the use of this limited healthcare resource while advocating for the welfare of their patients.

\section{Abbreviations \\ ICU: Intensive care unit; HEMS: Helicopter emergency medical services; IFT: Interfacility transport; GEM: Ground emergency medical services; ALS: Advanced life support; BLS: Basic life support}

\section{Acknowledgements}

Not applicable

\section{Authors' information}

Hasan is a medical student in the Schulich School of Medicine Class of 2022. He is passionate about improving healthcare delivery and resource stewardship. Dr. Taneja is a faculty member in the Division of Critical Care at Western University. His focus is on patient-centered care and costeffectiveness.

\section{Authors' contributions}

All authors read and approved the final manuscript.

\section{Funding}

The Summer Research Training Program (SRTP) at the Schulich School of Medicine, and the Internal Research Fund, Department of Anesthesia, Western University funded this research project. This funding award had no role in the design of this study or in writing of the manuscript.

Availability of data and materials

Not applicable

Ethics approval and consent to participate

Not applicable

Consent for publication

Not applicable

Competing interests

The authors declare that they have no competing interests.

Received: 14 March 2020 Accepted: 21 March 2020

Published online: 16 April 2020

\section{References}

1. Nickerson C. Air ambulance and critical care transport resource allocation process review. Emergency Health Services: British Columbia; 2014. http:// www.bcehs.ca/about-site/Documents/Report-Air-Ambulance-and-CriticalCare-Transport-Resource-Allocation-Process-Review.pdf. Accessed 30 Jan 2020

2. Petrie DA, Tallon JM, Crowell W, Cain E, Martell P, McManus D. Medically appropriate use of helicopter EMS: the mission acceptance/triage process. Air Med J. 2007;26(1):50-4

3. Maclsaac M. Ontario's emergency health services - sector review: Ministry of Health and Long-Term Care; 2018. https://agendasonline.greatersudbury.ca/ index.cfm?pg=feed\&action=file\&agenda=report\&itemid=4\&id=1278. Accessed 30 Jan 2020 
4. Walcott BP, Coumans JV, Mian MK, Nahed BV, Kahle KT. Interfacility helicopter ambulance transport of neurosurgical patients: observations, utilization, and outcomes from a quaternary level care hospital. PLoS One. 2011;6(10):e26216. https://doi.org/10.1371/journal.pone.0026216.

5. Jones A, Donald MJ, Jansen JO. Evaluation of the provision of helicopter emergency medical services in Europe. Emerg Med J. 2018;35(12):720-5.

6. Nicholl J, Turner J, Stevens K, O'keeffe C, Cross L, Goodacre S, Snooks H. A review of the costs and benefits of helicopter emergency ambulance services in England and Wales: Final report to the Department of Health. University of Sheffield: Medical Care Research Unit; 2003. https:/www. sheffield.ac.uk/polopoly_fs/1.44101!/file/MCRU-HEASrev-2003.pdf. Accessed 30 Jan 2020.

7. Borst GM, Davies SW, Waibel BH, Leonard KL, Rinehar SM, Newell MA, Goettler CE, Bard MR, Poulin NR, Toschlog EA. When birds can't fly: an analysis of interfacility ground transport using advanced life support when helicopter emergency medical service is unavailable. J Trauma Acute Care Surg. 2014;77(2):331-7.

8. Karanicolas PJ, Bhatia P, Williamson J, Malthaner RA, Parry NG, Girotti MJ, Gray DK. The fastest route between two points is not always a straight line: an analysis of air and land transfer of nonpenetrating trauma patients. J Trauma Acute Care Surg. 2006;61(2):396-403.

9. Special Report: Ornge air ambulance and related services. Office of the Auditor General of Ontario; 2012. http://www.auditor.on.ca/en/content/ specialreports/specialreports/ornge_web_en.pdf. Accessed 30 Jan 2020.

10. Taylor CB, Stevenson M, Jan S, Middleton PM, Fitzharris M, Myburgh JA. A systematic review of the costs and benefits of helicopter emergency medical services. Injury. 2010;41(1):10-20.

11. Doucet J, Bulger E, Sanddal N, Fallat M, Bromberg W, Gestring M. Appropriate use of helicopter emergency medical services for transport of trauma patients: guidelines from the Emergency Medical System Subcommittee, Committee on Trauma, American College of Surgeons. J Trauma Acute Care Surg. 2013;75(4):734-41.

12. United States Environmental Protection Agency. 2018 https://www.epa.gov/ greenvehicles/greenhouse-gas-emissions-typical-passenger-vehicle. Accessed 30 Jan 2020.

13. Conklin \& de Decker Aviation Information Database. https://www.conklindd. com/CDALibrary/CO2Calc.aspx. Accessed 30 Jan 2020.

14. Brown JB, Stassen NA, Bankey PE, Sangosanya AT, Cheng JD, Gestring ML. Helicopters improve survival in seriously injured patients requiring interfacility transfer for definitive care. J Trauma Acute Care Surg. 2011;70(2): 310-4.

15. Fatahi A, Donmez B, Ahghari M, MacDonald RD. Air versus ground vehicle decisions for interfacility air medical transport. In: Lim G, Herrmann JW, editors. Proceedings of the 2012 Industrial and Systems Engineering Research Conference. Orlando. Norcross: Institute of Industrial and Systems Engineering. 2012. p. 1-8. https://hfast.mie.utoronto.ca/wp-content/uploads/ Publications/5_Fatahi_Donmez_Ahghari_MacDonald_ISERC_2012.pdf. Accessed 30 Jan 2020

\section{Publisher's Note}

Springer Nature remains neutral with regard to jurisdictional claims in published maps and institutional affiliations. 